
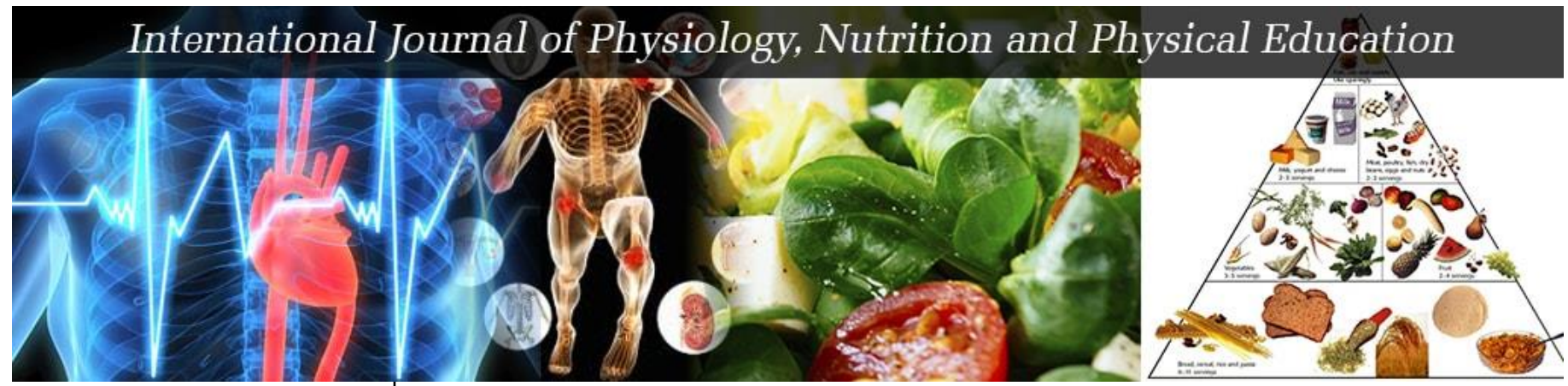

ISSN: 2456-0057

IJPNPE 2020; 5(2): 22-25

(C) 2020 IJPNPE

www.journalofsports.com

Received: 19-05-2020

Accepted: 22-06-2020

Dipendra Pratap Rana

MPT, Laxmi Memorial College of

Physiotherapy, Mangalore,

Karnataka, India

Sanjay Eapen Samuel

Professor \& Principal, Laxmi

Memorial College of

Physiotherapy, Mangalore,

Karnataka, India

Shridhar Shetty

Professor and Head, Department of Orthopaedics, A J Institute of

Medical Sciences, Mangalore,

Karnataka, India

Cyanna Joseph D'souza

Lecturer, Laxmi Memorial

College of Physiotherapy,

Mangalore, Karnataka, India

\section{Immediate effect of static stretching versus dynamic stretching of the hamstring muscle in recreational college athletes}

\author{
Dipendra Pratap Rana, Sanjay Eapen Samuel, Shridhar Shetty and \\ Cyanna Joseph D'souza
}

DOI: https://doi.org/10.22271/journalofsport.2020.v5.i2a.1957

\section{Abstract}

Background: Support for dynamic stretching has grown in recent years, because several investigations show the potential for acute static stretching to degrade athletic performance. The hamstring muscle is the most frequent and disabling musculotendinous strain among athletes. Hence, this study aimed to compare the effectiveness of Static Stretching (SS) and Dynamic Stretching (DS) in acutely improving hamstring flexibility among recreational college athletes.

Methodology: 72 male recreational athletes of mean age $23.59 \pm 1.55$ years with limited hamstring flexibility were randomly assigned to either SS or DS groups. Athletes in the SS group performed one single static stretch for 30 seconds and those in DS group performed six dynamic stretches for 30 seconds.

Results and Conclusion: A significant difference in hamstring flexibility was found between SS group $\left(3.60^{\circ}\right)$ and DS group $\left(8.12^{\circ}\right)(p<0.001)$. Hence, indicating that one session of DS through a full range of motion improved hamstring flexibility, better than SS.

Keywords: Flexibility, hamstring, stretching, warm-up

\section{Introduction}

Most experts consider aerobic conditioning, strength training, and flexibility as key components of a conditioning program ${ }^{[1,2]}$. By definition, flexibility is the ability of a muscle to lengthen and allow one or more joints to move through a range of motion (ROM), wherein loss of flexibility decreases the ability of a muscle to perform optimally ${ }^{[3]}$. Reduced injury risk $[1,2]$, pain relief, ${ }^{[4]}$ and improved athletic performance ${ }^{[5,6]}$ are reasons provided for incorporating flexibility training into a training program.

Although the necessity of a warm-up might be obvious, the specific elements that it should include may be less clear. Static stretching (SS), defined as elongation of a muscle to tolerance and sustaining the position for a length of time is considered the gold standard in flexibility training ${ }^{[7,8]}$. However, some authors have questioned the role of SS in reducing injuries and improving athletic performance ${ }^{[1,2]}$. Recent studies have found SS an ineffective way to reduce injury rates ${ }^{[9,10]}$, and may actually inhibit athletic performance ${ }^{[11]}$. Although used as a part of preactivity preparation, Murphy argued that the nature of SS is passive and does nothing to warm a muscle ${ }^{[12]}$.

An alternative for improving flexibility, according to Murphy, would be an activity that is more dynamic in nature. He therefore coined the term "dynamic range of motion." To dynamically stretch a muscle, the antagonist group is contracted allowing the agonist to elongate naturally in a relaxed state ${ }^{[12]}$. The dynamic nature of the activity, would cause a warming effect in the muscle, and the muscle would be more pliable and accommodating to the stretch, leading to an increase in its flexibility ${ }^{[25]}$. Additionally, it also promotes muscle strength as the movement is being performed by the muscles that actively move the involved joint ${ }^{[24]}$. Likewise, a number of studies have proven that Dynamic Stretching (DS), in comparison to SS, would result in higher flexibility gains ${ }^{[13-15]}$.
Corresponding Author: MPT, Laxmi Memorial College of Physiotherapy, Mangalore,

Karnataka, India 
The hamstring muscle is most susceptible to injury and represents a significant portion of lower extremity musculotendinous injuries in athletic competitions [16, 17]. Hamstring muscle injury is a complex problem for athletes, physicians, physical therapists, and athletic trainers as these injuries tend to recur and limit participation ${ }^{[18]}$. The etiology of this injury continues to be obscure for clinicians and researchers [19]. Several authors have investigated the relationship between hamstring flexibility and hamstring injury [16, 19]. Worrell et al. ${ }^{[6]}$ and Liemohn ${ }^{[20]}$ reported hamstring-injured subjects were less flexible. In contrast, Ekstrand reported no difference in hamstring flexibility between hamstring injured and non-injured subjects ${ }^{[16]}$.

Given the debate on SS before sports practice and competition, there is a distinct need for additional research evaluating the effects of different warm-up treatments on improving flexibility of young athletes. Recreational athletes, as compared to trained athletes do not undergo regular training or sufficient pre-event warm-up, which is an absolute necessity before any sporting activity in order to prevent injuries [21]. Therefore, the objective of this study was to compare the effect of SS and DS in acutely improving hamstring flexibility in recreational college athletes.

\section{Methodology}

\subsection{Study design and Participants}

Seventy-two participants at Laxmi Memorial College of Physiotherapy, Mangalore were recruited on a voluntary basis to participate in this descriptive comparative study. The study was approved by the Institutional Ethical Committee and an informed consent was obtained from all participants. This study is part of a trial which evaluated hamstring length with other variables following stretching.

All study subjects were male athletes between ages 20 to 30 years that competed at lower levels such as college and intercollege competitions and did not participate in any type of regular physical training in the last 2 years. Volunteers had to exhibit hamstring tightness defined as a deficit of $20^{\circ}$ from full knee extension with the hip at $90^{\circ}$. The exclusion criteria included: elite athletes, low back pain or a history of lower extremity injuries that required treatment or that might have inhibited performance in last 12 months, lumbar spine or any lower extremity surgery in the last 6 months.

\subsection{Sample size and Sampling}

A sample size was estimated with $95 \%$ confidence level and $90 \%$ test power based on the study by Nelson RT. ${ }^{13}$ in which the combined standard deviation $(\sigma)$ was 5 and mean difference $(d)$ was 3.9. This showed that the ideal sample size for the study would be 72 . The subjects were recruited using convenience and randomly assigned to two groups using concealed envelope method. Group I received Static Stretching (SS) and Group II received Dynamic Stretching (DS).

\subsection{Interventions}

Subjects in the SS group $(n=36)$ performed a single 30 second static stretch using the method described by Bandy et al. ${ }^{1,22}$ The subject performed the stretch by standing erect with the left foot on the ground, toes pointed forward. The heel of the right foot was placed on a stepper with the toes pointed towards the ceiling. The subject then flexed forward at the hips, while maintaining a neutral spine (Figure 1). The subject was instructed to keep the right knee fully extended and flexed forward at the hips until a gentle stretch was felt in the posterior thigh. The position of stretch was held for 30 seconds. The stretch was performed bilaterally.

The subjects in the DS group $(n=36)$ were instructed to lay supine with the left lower extremity fully extended. A 3 feet $(0.91 \mathrm{~m})$ piece of black theraband was held by the ends in each hand with the mid-section of the band wrapped around the right heel as described by Nelson et al. ${ }^{[13]}$ The exercise began with the right knee locked in full extension and the hip in 0 degree of extension (Figure 2a). The subject then pulled the hip into full flexion by pulling on the ends of the band with the arms and was asked to stop once he felt a gentle stretch (Figure 2b). The DS was performed 6 times for a total stretch of 30 seconds. The stretch was performed bilaterally.

\subsection{Outcome Measure}

Measurement of hamstring flexibility was performed using the 90-90 test described by Reese and Bandy ${ }^{[22]}$. The subjects were positioned supine with the hip and knee flexed to $90^{\circ}$ (Figure 3). The goniometer was aligned with the lateral malleolus and the greater trochanter and centered over the lateral epicondyle. The point at which the researcher felt a firm resistance was defined as terminal extension and the corresponding measurement on the goniometer was recorded. Full hamstring flexibility was zero degrees on the goniometer. The test was performed bilaterally and the average was used for analysis. The test was done before and after 5 minutes after intervention.

\subsection{Data analysis}

Statistical package SPSS (IBM SPSS Statistics for Windows, ver. 21.0. Armonk, NY: IBM Corp.) was used to analyze the data. The difference in baseline data (age and BMI) between each group was analyzed using unpaired t-test. The mean values of the pre and post 90-90 test between groups was compared using unpaired t-test. The Student's paired t-test was used to analyze between group comparison for 90-90 test. All probability ( $\mathrm{p}$ ) values in this study were calculated within a confidence interval of $95 \%$. p values less than 0.001 were considered statistically significant.

\section{Results and Discussion}

The mean age and BMI of the study participants was $23.59 \pm$ 1.55 years and $23.42 \pm 1.58 \mathrm{~kg} / \mathrm{m}^{2}$ respectively. There was no significant difference in the age $(p=0.68)$ and BMI $(p=0.96)$ between SS and DS groups (Table 1).

Unpaired t-test indicated that there was no significant difference in the 90-90 pre-test scores in either of the groups $(\mathrm{p}=0.50)$. However, a significant difference was found in the 90-90 post-test indicating improved hamstring flexibility in the DS group post intervention, and was found to be statistically significant ( $p<0.001)$ (Table 2).

There was an significant increase of 3.79 degrees and 8.27 degrees in the 90-90 test scores in the SS group and DS group respectively, indicating higher gains in hamstring flexibility in the DS group using the paired t-test ( $p<0.001)$ (Table 3 ).

The group performing one bout of DS showed a significantly greater gain in flexibility than the SS group. Similar findings were reported by Nelson et al. in their study comparing the acute effects of static versus eccentric stretching ${ }^{[4]}$. Likewise, Aguilar et al. also found that a dynamic warm-up consisting of both stretching and running was effective in improving hamstring flexibility rather than a SS warm-up in recreational soccer players ${ }^{[15]}$.

DS has been shown to improve flexibility not only from one bout of training as in this study, but also over a six week 
training program. ${ }^{1}$ The gains achieved by a six week program of SS and a six week program of dynamic training were very similar. Static training gained $12.04^{\circ}$ and eccentric training gained $12.79^{\circ}$ over the six week training program ${ }^{[1]}$. On the other hand, William et al. found that 30 seconds of SS increased ROM more than two times when compared with 30 seconds of DS, questioning the use of dynamic training in improving muscle flexibility ${ }^{[16]}$.

No studies to date have examined the use of dynamic training to reduce injury rates, but the SAID (Specific Adaptation to Imposed Demand) principle states if the muscle adapts to the imposed demands of dynamic training, injury rates would be lower since most injuries occur during the dynamic phase of activity. Strength gains from dynamically training a muscle would, theoretically, also improve performance ${ }^{[1]}$. In addition, dynamic training is strengthening the muscle by having it contract as it lengthens. An individual dynamically training through a full ROM will be gaining range and strength at the same time, thus, making the activity more functional. This type of training could also save time since it combines strengthening and flexibility components into one activity ${ }^{[13]}$.

Previous authors have proposed two hypotheses for the static stretching-induced decrease in performance: (a) mechanical factors involving the viscoelastic properties of the muscle that may affect the muscle's length-tension relationship and (b) neural factors such as decreased muscle activation or altered reflex sensitivity ${ }^{[6,10]}$. Studies have also suggested that the primary mechanism underlying the stretching-induced decreases in force is related to increased muscle compliance that may alter the muscle length-tension relationship, increase sarcomere shortening distance and velocity, and decrease force production due to the force-velocity relationship ${ }^{[8,10]}$.

The above discussion shows that further research is needed to determine if tangible gains can be made in strength, injury reduction, and performance enhancement through the use of dynamic training. Since, the participants in this study belong to various sports; the results of this study should be confirmed in sport-specific athletes. The results of this study can be further confirmed in larger and more diverse populations including women, professional athletes and in the middleaged. Also, the effect of stretching on other major muscle groups of the lower limb other than hamstring muscle should be studied.

Various stretching and warm-up methods have been utilized to enhance muscle flexibility. The results of this study apply only to the dynamic stretching protocol used here. However, these findings could not show how long the immediate effect on flexibility would last. This problem will need to be investigated in the future to clarify the efficacy of a warm-up program that includes dynamic stretching.

\section{Tables and Figures}

Table 1: Distribution of subjects in SS group and DS group based on age and BMI using unpaired t-test

\begin{tabular}{|c|c|c|c|c|c|c|}
\hline & Group & $\mathbf{N}$ & Mean & Standard Deviation & t value & p value \\
\hline \multirow{2}{*}{ Age $($ years) } & Group I & 36 & 23.65 & 1.52 & \multirow{2}{*}{403} & \multirow{2}{*}{0.68} \\
\cline { 2 - 6 } & Group II & 36 & 23.47 & 1.60 & \multirow{2}{*}{.051} & \multirow{2}{*}{0.96} \\
\hline \multirow{2}{*}{ BMI $\left(\mathrm{kg} / \mathrm{m}^{2}\right)$} & Group I & 36 & 23.42 & 1.53 & 1.65 & \\
\cline { 2 - 6 } & Group II & 36 & 23.40 & & & \\
\hline
\end{tabular}

Table 2: Mean values of the Pre and Post 90-90 Test in the SS group and DS group using unpaired t-test

\begin{tabular}{|c|c|c|c|c|c|c|}
\hline & Group & $\mathbf{N}$ & Mean & Standard deviation & t value & p value \\
\hline \multirow{2}{*}{ Pre test } & Group I & 36 & 26.65 & 3.90 & \multirow{2}{*}{.615} & \multirow{2}{*}{0.5} \\
\cline { 2 - 8 } & Group II & 36 & 27.22 & 3.67 & \multirow{2}{*}{4.422} & \multirow{2}{*}{.000} \\
\hline \multirow{2}{*}{ Post test } & Group I & 36 & 22.93 & 3.65 & 3.77 & \\
\cline { 2 - 7 } & Group II & 36 & 18.94 & &
\end{tabular}

Table 3: Gain scores 90-90 Test in the SS group and DS group using Student's paired t-test

\begin{tabular}{|c|c|c|c|c|c|}
\hline \multicolumn{2}{|c|}{ Group } & \multicolumn{2}{|c|}{ Paired Differences } & \multirow{2}{*}{ t value } & \multirow{2}{*}{ p value } \\
\cline { 2 - 4 } & & Mean & Standard Deviation & & \\
\hline Group I & $90-90$ pre test - 90-90 post test & 3.719 & 1.420 & 14.819 & .000 \\
\hline Group II & $90-90$ pre test - 90-90 post test & 8.278 & 1.111 & 44.694 & .000 \\
\hline
\end{tabular}

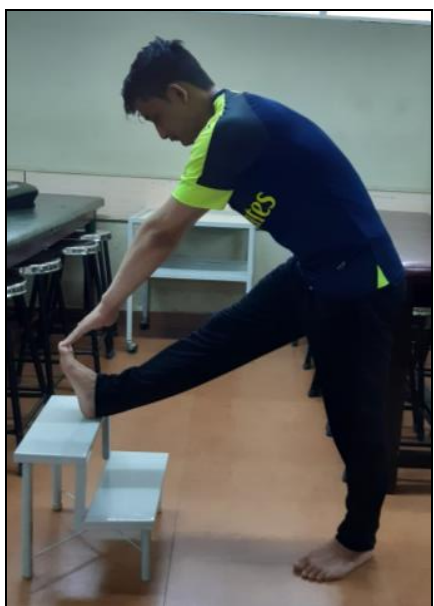

Fig 1: Static Stretching position

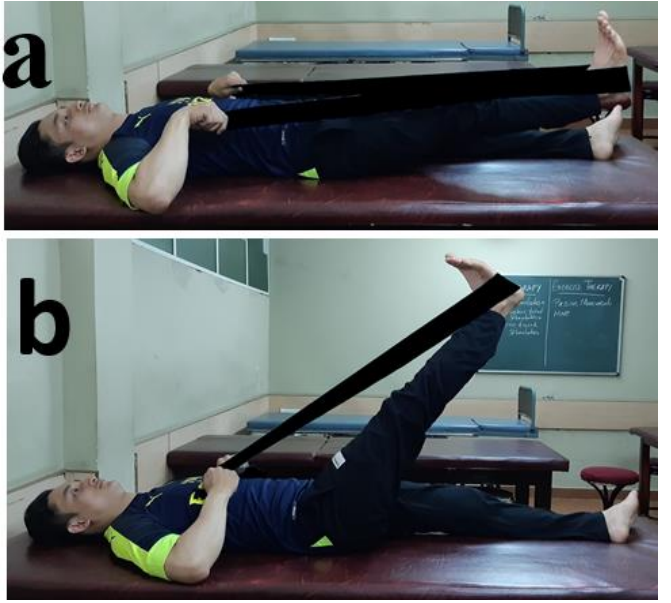

Fig 2: Dynamic Stretching; $a$ = initial position; $b$ = final position 


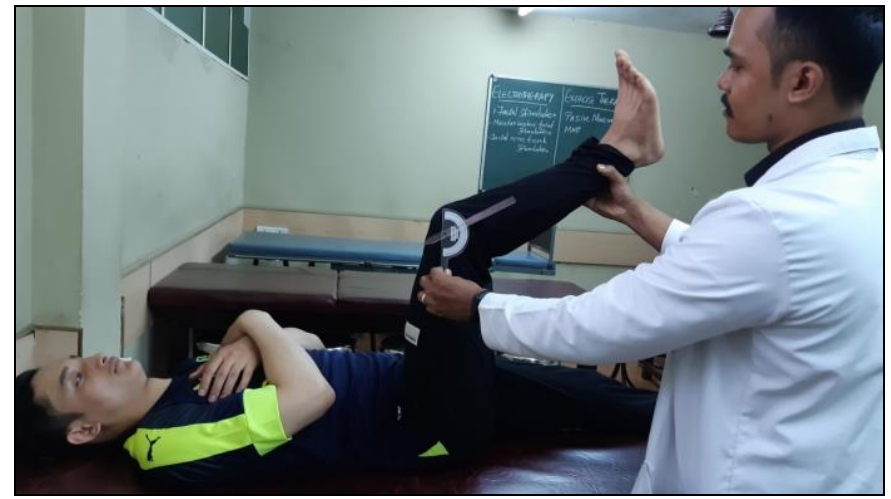

Fig 3: 90-90 test to assess for hamstring flexibility

\section{Conclusion}

The DS protocol used in this study is more effective than SS in immediately improving hamstring flexibility in recreational athletes. The dynamic stretching method used in this study is simple and easy to incorporate into a warm-up routine. Therefore, based on these findings, it can be recommended that therapists and athletic coaches consider incorporating dynamic stretching in their warm-up routine, with the hope of enhancing the athlete's hamstring muscle flexibility.

\section{Funding/Support}

The authors declare that no funding was provided for this study.

\section{Acknowledgement}

We would like to express our gratitude to the study participants and are thankful to the statistician, Mr. M.S. Kotian for his invaluable contribution to the study and also to the teaching staff of our institute for their support and guidance.

\section{References}

1. Bandy WD, Irion JM, Briggler M. The effect of time and frequency of static stretching on flexibility of the hamstring muscles. Phys Ther. 1997; 77(10):1090-6.

2. Halbertsma JP, van Bolhuis AI, Goeken LN. Sport stretching: Effect on passive muscle stiffness of short hamstrings. Arch Phys Med Rehabil. 1996; 77(7):688-92.

3. Zachezewski JE. Improving flexibility. In: Scully RM, Barnes MR, eds. Physical Therapy. Philadelphia, PA: JB Lippincott Co, 1989, 698-99.

4. Henricson AS, Fredriksson K, Persson I, Pereira R, Rostedt Y, Westlin NE. The effect of heat and stretching on the range of hip motion. J Orthop Sports Phys Ther. 1984; 6(2):110-5.

5. Anderson B, Burke ER. Scientific medical and practical aspects of stretching. Clin Sports Med. 1991; 10(1):6386.

6. Worrell TW, Smith TL, Winegardner J. Effect of hamstring stretching on hamstring muscle performance. J Orthop Sports Phys Ther. 1994; 20(3):154-9.

7. Iashvilli AV. Active and passive flexibility in athletes specializing in different sports. Teorig Praktika Fizicheskoi Kultury. 1987; 7(3):51-2.

8. Egan AD, Cramer JT, Massey LL, Marek SM. Acute effects of static stretching on peak torque and mean power output in National Collegiate Athletic Association Division I women's basketball players. J Strength Cond Res. 2006; 20(4):778-82.

9. Thacker SB, Gilchrist J, Stroup DF, Kimsey CD. The impact of stretching on sports injury risk: A systematic review of the literatures. Med Sci Sports Exerc. 2004; 36(3):371-8.

10. Herbert RD, Gabriel M. Effects of stretching before and after exercising on muscle soreness and risk of injury: Systematic review. Br Med J. 2002; 325:468.

11. Shrier I. Does stretching improve performance? A systematic and critical review of the literature. Clin $\mathbf{J}$ Sport Med. 2004; 14(5):267-73.

12. Murphy DR. A critical look at static stretching: Are we doing our patient harm? Chiropractic Sports Med. 1991; 5(2):67-70.

13. Nelson RT. A comparison of the immediate effect of eccentric training vs. static stretch on hamstring flexibility in high school and college athletes. N Am J Sports Phys Ther. 2006; 1(2):56-61.

14. O'Sullivan K, Murray E, Sainsbury D. The effect of warm-up, static stretching and dynamic stretching on hamstring flexibility in previously injured subjects. BMC Musculoskelet Disord. 2009; 10:37.

15. Aguilar AJ, DiStefano LJ, Brown CN, Herman DC, Guskiewicz KM, Padua DA. A dynamic warm-up model increases quadriceps strengthening and hamstring flexibility. J Strength Cond Res. 2012; 24(4):1130-41.

16. Ekstrand J, Gillquist J. The frequency of muscle tightness and injuries in soccer players. Am I Sports Med. 1982; 10(2):75-8.

17. Mann R, Sprague P. A kinetic analysis of the ground leg during sprint running. Res Q Exerc Sport. 1980; 51(2):334-48.

18. Christensen C, Wiseman D. Strength: The common variable in hamstring strain. Athl Train. 1972; 7(2):3641.

19. Worrell TW, Perrin DH. Hamstring Muscle Injury: The Influence of Strength, Flexibility, Warm-Up, and Fatigue. J Orthop and Sports Phys Ther. 1992; 16(1):12-8.

20. Liemohn W. Factors related to hamstring strains. J Sports Med Phys Fitness. 1978; 18(1):71-6.

21. Burkett LN, Phillips WT and Ziuraitis, J. The best warmup for the vertical jump in college-age athletic men. J Strength Cond Res. 2005; 19(3):673-6.

22. Bandy WD, Irion JM, Briggler M. The effect of static stretch and dynamic range of motion training on the flexibility of the hamstring muscles. J Orthop Sports Phys Ther. 1998; 27(4):295-300. 